Glazer, Judith S., Bensimon, Estela M., \& Townsend, Barbara K. (Eds.). Women in Higher Education: A Feminist Perspective. ASHE Reader Series. Needham Heights, MA: Ginn Press, 1993. Pages: xvii, 600 with bibliography. Reviewed by Dr. Jane Gordon, Department of Sociology/Anthropology, Mt. St. Vincent University, Halifax.

This is a massive volume, containing an introduction, forty separate articles, each with appropriate notes and references and a concluding thematic bibliography. It runs 600 full-size $81 / 2$ by 11 pages. The material is organized into four sections, some of which have a sub-organizational structure. This is a weighty volume in more ways than one.

Let me say at the outset that this volume contains an extensive and valuable literature on women in post-secondary education, discussing many significant issues. That is both the strength and the weakness of this book. As I travelled (or travailed) through the volume I observed aspects of the following which require further comment prior to consideration of the actual contents: physical presentation of the book, Canadian research, and intended audience or uses of the book.

In a practical sense, this book is very difficult to use. Its size makes it both heavy and awkward to read. It is quite heavy by actual weight. The size contributes to its difficulty of use. It is a standard $81 / 2$ by 11 page in size, and about an inch and a quarter thick. The text is presented in single spaced typed writing across the page. Holding the book itself is as good as an exercise in weight lifting. The spine is not flexible. It is impossible to fold back the pages in any useful way while reading and the binding does not allow the book to rest open very easily. The physical presentation of the volume detracts from its merits and makes the reading unwieldy and a chore, even when one is interested in the content. The presentation of the book limits accessibility of and to the book.

If I consider the question of the intended readership, some of the answers are obvious. The book will be a resource for university and college libraries. It may even be in the personal library of those interested in issues of women and education. It is unlikely, however, that the circulation will be wider than that. The contents merit a wider audience. Constituencies who might find this book valuable include women students, faculty, those teaching or interested in higher education, women's issues, history of ideas or the sociology of knowledge, epistemology or philosophy of knowledge. The presentation format of the book means that many potential readers who would welcome the information are not likely to have access to it. A general interest audience as well as a professional one would have been better served by the presentation of this material as two or 
three separate volumes. And I have not even considered questions of price or availability of the volume.

There is one other caution I would like to mention for readers of the Canadian Journal of Higher Education. The forty-ninth parallel appears to be impermeable, as least as far as the movement south of consideration of Canadian scholarship. The book is clearly and singularly American. Dorothy Smith of the Ontario Institute for the Study of Education is cited four times, only once from a Canadian publication. An old (1949) article published in the American Journal of Sociology by Oswald Hall was mentioned once. It was not until the last of 40 articles that there was one co-authored by scholars based in Canada - and this article had originally appeared in the Harvard Education Review. Except for one Smith citation from the Canadian Review of Sociology and Anthropology, Canadian scholarship was only cited when it appeared in American or international journals or books.

There are several possible explanations for the absence of Canadian scholarship. Three possible ones are (a) the practices of the compilers of the indices to scholarly sources which largely exclude Canadian material, (b) the unavailability of Canadian books and scholarly journals even if researchers had appropriate citations and (c) the choice of scholars to dismiss the contents of such publications as insignificant even if available. Whatever the explanation, it is unfortunate. There is useful and appropriate scholarly research done in this country, some of it published in this journal; however there is no evidence of this scholarship in this book, not reprinting of material or citation of it. In contrast, the bibliography in Canadian Paula Caplan's Lifting a Ton of Feathers has a significant number of Canadian references on many of the same themes.

There are forty articles in this reader. Although the genesis of the volume was a conference, the articles which appear are not the conference papers. Rather, the editors develop the theme of the conference, "Feminist Scholarship in Higher Education," through re-publication of previously published research. Articles originally appeared between 1979 and 1992. The sources culled for this selection and the criteria by which the particular articles were selected are not described.

Clearly the works, although already in the public domain, represent ideas at very different stages of development. Some of the articles are selections from previously published books (for example, Aisenberg \& Harrington's Women of Academe: Outsiders in the Sacred Grove or Gilligan's In a Different Voice). Others represent publication of portions of research findings which, subsequent to their original publication in a journal, became part of a book (for example,, Holland \& Eisenhart's selection eventually was in their book, Educated in Romance.) Selections are drawn from anthologies, journals and research reports and policy documents. 
The material is eclectic in purpose as well. The subject matter is varied, but so is the purpose for which the material has been written. There are conventional academic research papers, philosophical considerations, policy oriented material, and personal narratives. The articles are organized into five distinct but broadly defined sections, each of which attempts to provide varied views of its particular topic.

\section{Discussion of Content}

The four broad section of the book are (1) Theoretical and Research Perspective, (2) Context - Historical, Social, Professional, Institutional, (3) Women in Academe: As Students, Faculty, Administrators and Trustees, and (4) The Transformation of Knowledge: Curricular Change and Feminist Pedagogy. The sections contain either 6 or 7 articles, with the exception of (3), which has three parts, 'The Woman College Student' (9 articles), 'Women Faculty and the Professoriate' ( 7 articles) and 'Women Administrators and Trustees: Governing the University' ( 5 articles). This enumeration, in itself, provides an interesting commentary on where research has been done. An overview of the material in each section will better inform the reader of the contents.

\section{(1) Theoretical and Research Perspective}

This section is the most abstract of the book as a whole, although the articles represent analysis of different issues. The issues covered include discussion of the variety of theoretical perspectives which can be used in the study of women in higher education, the consequences of using models built on male experiences for assessing women's experiences and responses, the relevance of considering marginalised perspectives, and issues of gender and organizational behaviour and research. These articles are, of necessity, drawn from the disciplines of their authors. The language and paradigms used are not always easily understood by those with other backgrounds. This problem often occurs in multidisciplinary books and can be overcome with careful editing or introductory sections, although it has not occurred here.

The lack of consistency in the background necessary to understand each article results from the manner in which the material for this book was assembled. The book reprints valuable material from diverse sources. However topically appropriate, this process means that diversity is also reflected in language, frameworks and methodologies.

Many of the articles in the first section draw on concepts which a general reader may lack, however well educated or involved in higher education. However, Perreault's article on the theoretical frameworks involved in studying 
higher education is an example of one in which the author defines her concepts and explains her points clearly enough so that a reader who had no background in theory can understand the material. Similarly Collins discusses a literature which is unknown to me and to the majority of readers of this journal. However, she is clear about the focus of her work and the direction of her thinking is evident, even when the material is unknown. In contrast, Acker's article is written not just for sociologists but for sociologists of organizational behaviour. Those of us not familiar with the speciality will at best move very slowly through the paper; at worst will skip it, or will struggle for comprehension.

This same variation occurs in other sections, although it is more problematic in the first section because of its focus. Issues of theory and methodology are an essential dimension in understanding feminist perspectives on education. They have often been placed at the beginning of anthologies as appropriate introductory material to the subject. In this volume, however, that arrangement serves to deter two categories of potential readers. Those interested in higher education in a general way are likely distracted by the initial debates in feminist analysis which are new to them, and may seem unnecessarily pedantic or navel gazing. On the other hand, for readers with more background on women in the academy, these articles are reviews of existing frameworks, not new insights. They form a rather ponderous opening to the book.

\section{2) Context - Historical, Social, Professional, Institutional}

This section raises some important issues and contains a great deal of useful analysis and insight into issues of women in the academy. However, the section is not entirely successful at providing an adequate historical and sociological context for current issues of accessibility, equity and voice for under-represented groups in the academy. This is best illustrated through discussion of the specific articles.

The section leads off with Rich's almost classic description of a womancentered university. The essay appeared in a collection published in 1979, with selections drawn from between 1966 and 1978. This essay originally appeared in 1973 or 1974 . Some of the dimensions of a woman-centered university originally described by Rich have come to be accepted parts of current university life: child care is available on campus, students study part-time, and there is flexibility about access to education at different stages of the life cycle. Others, however, are still elusive. This essay tells us more about what the issues were prior to 1979 than it does about the contemporary situation. In that sense it is a historical document, although it is a political rather than an historical analysis. If one may stretch the analogy a bit, it is like having a selection from Tocqueville's 
Democracy in America as background to a discussion on contemporary American society. Useful historical insights, yes; historical background, no.

In contrast, Clifford's article which follows does provide background which contributes to our understanding of issues around the development of coeducation in American colleges and universities, of the impact of women on the programs and politics of colleges, of the resulting issues of climate, and of some of the contradictions which emerged. Clifford points out, for example:

Although many institutions had provided housing and other services to male veterans and tuition grants to the children of male faculty, provisions for child care for women students and faculty would be resisted as an unwise intrusion of the personal and familial sphere upon the intellectual and professional character of the university (p. 167)

Clifford's article helps in understanding issues around women's access to higher education. Rich's advocates. Both are useful, nonetheless the perspective provided in this section on the history of women's education is very limited.

The other articles in this section do not add to our historical understanding, although some of them do provide some useful background. Sandler's paper on the campus climate for women faculty and administrators is also a classic. Yet it continues to be relevant because it provides touchstones against which climate can be assessed and reassessed. This article is well worth reading on a periodic basis, if only to remind us of areas requiring sensitivity.

Moore and Sagaria write about women in research universities, a useful reminder of the hierarchies among universities. An overview, particularly of American statistics, may be misleading. While national figures can look good, further analysis may present a different picture. Women may be located in the two-year and less prestigious colleges, which are the teaching oriented institutions, and yet be virtually non-existent at the major research and graduate training universities.

The placement of the two other articles, however, is more questionable. One is on sexual harassment, and the other on Hispanic women. Each of these articles could fit more easily into other sections of the book. It is likely they are placed here simply to get a better page balance between sections. This has meant a limit on more thematic articles and, in fact, detracts from the theme.

The placement also indicates that what is lacking is an adequate development of a section on context. A better discussion of the larger context would contribute to understanding the ways in which women challenge deeply rooted traditions and practices in the academy. These practices need to change and they are changing. However, understanding the context is still important in understanding the history and resistance to change. 


\section{(3) Women in Academe: As Students, Faculty, Administrators and Trustees}

This part of the book is further subdivided into categories, by status in the university. Its relative length suggests that it is more interesting for academic researchers to study themselves, and the people with whom they interact, than to focus on more abstract issues.

The section on women students is the longest because of the inclusion of perspectives from the most numerous minority groups in the United States. There are two articles on the experience of black women in post-secondary education, one on Asian women and another on American Indian women. (Hispanic women have been previously discussed in the section on context, an artificial division which seems more practical than appropriate.)

One of the persistent themes in these articles is the limitation of accessibility to higher education. It is interesting that the characteristic analyzed to define restricted opportunities to education is minority ethnic identity rather than structural dimensions of education. The second most commonly considered restrictive factor is questions of pedagogy and epistemology. Styles of teaching and learning also are considered in the final section; again, another example of poorly justified organization.

These are certainly factors which limit participation in education, but my training as a sociologist suggests there are other aspects which are probably more significant. The analysis excludes variables which affect educational participation rates, only one of which is race; and it also fails to examine characteristics of the educational setting which have been identified as having an impact on gender composition. The section does not consider issues like costs, child care, program characteristics (for example, time limitations on completion of requirements), physical environment including campus safety, sexual harassment, campus based sexual assault, or the maleness of the environment significant to understanding the student experience. Some of these topics are covered elsewhere but their systematic operation as barriers to women students is invisible precisely because of their dispersion. It may be that to focus on personal attributes rather than structural ones is an approach more congruent with American culture's individualistic orientation. Canadian students protesting efforts to transform the higher education system here at least acknowledge the impact of structural factors when they object to policies which would result in increased tuition.

From a policy-making perspective many of the chapters provide specific recommendations for increasing accessibility. Although these are described in terms of the needs of particular groups, they are useful for educational institutions to consider more generally. Efforts to increase diversity in Canadian 
higher education have focused on aspects of the organization not characteristics of the individual. Some consideration of minority individual or group need is obviously important as these groups continue to have low participation rates. Many of the suggestions here would be quite helpful for campuses working on increasing diversity. However, the policy suggestions are also not helpful for dealing with systemic obstacles such as the cost of education.

The section on women faculty provides a far better perspective on the systemic difficulties women faculty face. The selection by Aisenberg and Harrington describes the challenge women have in understand the real rules of the game in academic life, and the resulting choices they must make assuming merit, not politics, is the real criterion of success. Sadly they point out:

...women academics who do receive helpful career advice or direction often receive it from other women. But then there is another, sadder dimension to the role of the woman mentor in contributing to the advancement of younger women, and that is the relative weakness or insecurity in many cases of the mentor's own position. (p. 392)

Or, as Clark and Corcoran describe it, in the same section, it is the Matthew effect. ("For whosoever hath, to him shall be given, and he shall have more abundance; but whosoever hath not, from him shall be taken away even that he hath" quoted on page 401 from the King James Version of the Bible, Matt. 25:29.) This is considered fair in academic life, even as it perpetuates inequalities. The Matthew effect has a particularly heinous effect on women, as Clark and Corcoran, Aisenberg and Harrington, and the other articles point out. This portion of the book is one of the most useful of this anthology. Two articles mentioned earlier, one on salaries by a committee of the American Association of University Professors, and one on research productivity by Astin and Davis, merit reading by all administrators and faculty who want to understand what women faculty experience.

The third section on women in administration and as board members also contains some insightful articles. Bensimon's article rethinking what leadership means, and Astin and Leland's longitudinal examination of leadership among academic women, raise important issues for the academy as a whole. Sagaria's description of mobility among academic administrators provides evidence of the need for further study. She points out that internal mobility is the easiest and most visible path for satisfying affirmative action expectation; however, there are also differences in mobility between the three broad categories of administration: academic, student and administrative affairs. The type of institution is a further variable affecting access to administrative careers. 
While this last section tries to include a variety of different roles and educational settings, it is eclectic and lacks depth. Demographic descriptions of the women who served on governing boards are useful, but the more significant question is what difference it makes to institutional policy to have them there. This latter, is, of course, very difficult to study.

One can see this book and this section in particular as a stage in the development of feminist analysis of higher education. We need some basic information before the more rigorous questions can be asked. However, for a book to appear in 1993 still presenting mainly basic information is to ignore much of the more sophisticated scholarship and debate which has occurred.

(4) The Transformation of Knowledge: Curricular Change and Feminist Pedagogy

This section is perhaps the farthest reaching of all. It begins with an excerpt from Minnich's book Transforming Knowledge in which she analyzes what she sees to be conceptual errors in the formulation of thinking and their impact on curriculum. Minnich says, for example, that while we do not say 'white men's literature' we do discuss 'black women's literature'. This reflects and perpetuates:

...a kind of knowledge in which white men's literature is seen as literature-itself, the inclusive term, the norm, and the ideal. Other literatures are relegated to subcategories, or if brought into the 'mainstream' category, are improperly judged because they are placed against standards, closed within contexts and discourses, that not only did not include them in the first place but were founded by people who thought they ought to be excluded. (p. 526-27).

Her sketch of the persistence of such conceptual errors also documents the need for their elimination if curriculum is to become inclusive.

Schuster and Van Dyne document the stages of curriculum transformation, producing useful checks for educational institutions examining the content of what it is they teach. Their description of these stages parallels the point made above, which is that there is an evolution in the way in which issues about women in the academy are approached; and the descriptions in some of the articles represent only the earlier stage.

Higginbotham also discusses curriculum transformation but her concern is with inclusion of the black experience. Her contribution is interesting but less useful for a more sweeping examination of what it is we teach in higher education. Similarly the one selection clearly identified with a Canadian educational setting, O.I.S.E.'s Lewis and Simon, represents a dialogue between a graduate student and faculty member about gender in a seminar interaction. It is an fasci- 
nating discussion. My bias, however, would be to argue for a discussion of teaching in the undergraduate classroom. Changing the classroom environment for undergraduates is ignored regretfully, given the regular occurrence of research which suggests that there is a systematic bias in the treatment of female and male students, so that males get more of the class 'talk' time, more encouragement to provide their opinions and answer substantive questions and more praise for what they do say. It is these characteristics which dishearten many women students and discourage them from further study. A critical examination of the undergraduate classroom rather than the graduate seminar would have been valuable.

One of the points that became evident as I considered both the strengths and the weaknesses of this volume is that, for the majority of articles, no identification or institutional affiliation of the author(s) is provided. Nor is there a section with any biographic information on them. I would have liked to know something of their positions (are they faculty, administrators, freelance scholars or something else), disciplines and institutional affiliations. With the range of educational settings in the United States, this could have provided a very useful background against which to judge the work.

In the most obvious case, for example, bell hooks (sic) describes her graduate student experiences. Did these succeed in keeping her from finishing her degree and/or entering academic life? Has she become an academic by the back door, as it were, by virtue of her extensive writing? In a more practical way, the absence of such identifying data means I cannot contact an author for follow-up information. Nor can I judge the over-all collection to see what kinds of institutions the authors are drawn from, or where they are currently located. Are the women who write about Hispanics or Asian/Pacific women writing from geographical settings in which they are likely to interact with students from these social groups? Even if this missing information is not useful to tell readers about the authors, its absence reflects a casualness toward providing information which is regrettable.

In conclusion, and as stated earlier, this volume contains important and valuable material on women in American academic life. While I have criticized many aspects of the book, it does provide under one cover an overview of gender and higher education in the United States. Some of the material is useful in understanding these same issues in Canada, although Canadian researchers will also find a comparable literature on women in Canadian higher education. Regrettably, Canadian resources don't seem to reach American scholars in the same way that their material reaches us. 
The cost and physical size, however, probably make this volume unavailable to many who would benefit from the content. I would have liked to see a more manageable book with a more careful selection of material. Ten key articles (my suggestions: Clifford; Sandler; Moore \& Sagaria; Clichy \& Zimmerman; Smith, Aisenberg \& Harrington; Clark \& Corcoran; Astin \& Leland; Minnich, Schuster \& Van Dyne) would have accomplished as much as the whole current volume and in a much more accessible and reader-friendly way. We would then have a much more useful book, with the rest of the material still available in its original published form.

$\infty \infty \infty \infty \infty \infty \infty \infty \infty \infty$

Waite, P.B. The Lives of Dalhousie University, Volume One, 1818-1925: Lord Dalhousie's College. Montreal and Kingston: McGill-Queen's University Press, 1994. Pages: xii, 338. Price: $\$ 39.95$ (cloth).

Reviewed by Paul Axelrod, Faculty of Arts, York University.

The early history of Dalhousie University is unusual even by Canadian standards. Initiated in 1818 by Lord Dalhousie, the Lieutenant Governor of Nova Scotia, the "institution" took in not a single student until 1838, closed seven years later, and reopened on a continuing basis in 1863 . Its founding, intermittent death, and subsequent emergence as the leading centre of higher education in the Maritime provinces are the subjects of Peter Waite's engaging study, the first of two volumes.

This is a story that can only be told in the context of the religious and political history of Nova Scotia, and few are better equipped to tell it than Waite, a distinguished historian of the Maritime region. He guides the reader through the Nova Scotian nether world of sectarian and community rivalries, symbolized and perpetuated by the conflicts over the Dalhousie university project.

Established (unlike the Anglican controlled King's College) on the principle of "Religious Toleration", Dalhousie was dominated unofficially by Presbyterians, who themselves were deeply divided for the first half of the nineteenth century. Mistrustful of Dalhousie's ambitions, Baptists began Acadia College at Wolfville, Catholics opened St. Mary's College in Halifax, and Methodists established Mount Allison College in nearby Sackville, New Brunswick. As Waite notes, "A college with no denomination behind it, in a world where denominational rivalries and loyalties were a fundamental way of life, was almost doomed."(p. 35) Political and theological tensions cooled sufficiently for Dalhousie to reopen in the 1860 s, still as a non-sectarian institution; 